\title{
Intra-operative red blood cell transfusion and mortality after cardiac surgery
}

Eline A. Vlot ${ }^{1 *}$ D, Lisa Verwijmeren¹, Ewoudt M. W. van de Garde², Geoffrey T. L. Kloppenburg ${ }^{3}$, Eric P. A. van Dongen ${ }^{1}$ and Peter G. Noordzij ${ }^{1}$

\begin{abstract}
Background: Anemia in cardiac surgery patients has been associated with poor outcomes. Transfusion of red blood cells during surgery is common practice for perioperative anemia, but may come with risks. Little is known about the association between intra-operative transfusion and mortality in patients undergoing cardiac surgery.

Methods: Single centre historical cohort study in 2933 adult patients undergoing coronary surgery with or without aortic valve replacement from June 2011 until September 2014. To estimate the odds ratio for mortality in patients receiving intra-operative transfusion, a propensity score based logistic regression analysis was performed.

Results: Intra-operative transfusion was associated with a more than three-fold increased risk of 30-day mortality. Patients in the highest quartile of probability of transfusion were older (age 75 vs 66 ; $P<0.001$ ), had a higher EuroSCORE ( 6 vs $3 ; P<0.001$ ), had lower preoperative hemoglobin levels ( $7.6 \mathrm{vs} 8.9 \mathrm{mmol} /$; $P<0.001$ ), had combined surgery more often (CABG + AVR in $33.4 \%$ of cases vs $6.6 \%(P<0.001)$ and a longer duration of surgery (224 vs $188 \mathrm{~min} ; P<0.001$ ). The association between intra-operative transfusion and mortality persisted after adjustment for these risk factors (adjusted OR 2.6; $P=0.007$ ).

Conclusions: Intra-operative transfusion of red blood cells was found to be associated with increased mortality in adults undergoing coronary surgery. Preoperative patient optimization may improve perioperative outcomes by reducing the likelihood of requiring transfusion and thus its associated risk.
\end{abstract}

Keywords: Cardiac surgery, Blood transfusion, Postoperative mortality

\section{Background}

Blood loss reduces the oxygen delivery capacity due to hypovolemia and anemia. Healthy patients are able to increase tissue oxygenation by a physiologic increase in cardiac output and enhanced oxygen extraction from erythrocytes. In patients with coronary disease these compensatory mechanisms are limited and without treatment anemia may lead to myocardial ischemia and subsequent myocardial infarction. Anemia in cardiac surgery patients is common and has been associated with poor outcome [1-3]. During surgery, ongoing blood loss and hemodilution as a result of cardiopulmonary bypass $(\mathrm{CPB})$ causes low hemoglobin $(\mathrm{Hb})$ levels. Transfusion of red blood cells (RBC) is the current

\footnotetext{
*Correspondence: e.vlot@antoniusziekenhuis.nl

${ }^{1}$ Department of Anesthesiology, Intensive Care and Pain Medicine, St

Antonius Hospital, Koekoekslaan 1, 3430 EM Nieuwegein, The Netherlands

Full list of author information is available at the end of the article
}

standard practice for perioperative anemia, but $\mathrm{RBC}$ transfusion is not without risks. Historical cohort studies that evaluated the influence of RBC transfusion in patients with perioperative anemia have reported an increased risk for adverse events, including mortality [4-8]. Additionally, the optimal transfusion trigger in cardiac surgery patients is largely unknown $[9,10]$. Especially during surgery, patients may temporarily tolerate lower Hb levels as metabolism is low and oxygen needs are reduced due to hypothermia and anesthesia. Further insight in the risk of intraoperative RBC transfusion to treat anemia may aid cardiac anesthetists to further improve patient blood management. This study aimed to investigate the association between intraoperative RBC transfusion and mortality in patients undergoing coronary surgery.

(c) The Author(s). 2019 Open Access This article is distributed under the terms of the Creative Commons Attribution 4.0 International License (http://creativecommons.org/licenses/by/4.0/), which permits unrestricted use, distribution, and reproduction in any medium, provided you give appropriate credit to the original author(s) and the source, provide a link to the Creative Commons license, and indicate if changes were made. The Creative Commons Public Domain Dedication waiver (http://creativecommons.org/publicdomain/zero/1.0/) applies to the data made available in this article, unless otherwise stated. 


\section{Methods}

\section{Study design and population}

All patients who underwent isolated coronary artery bypass graft surgery $(\mathrm{CABG})$ or combined CABG and aortic valve replacement (AVR) from June 2011 until September 2014 in St. Antonius Hospital, Nieuwegein, The Netherlands, were eligible for inclusion in this historical cohort study. Local Medical Research Ethics Committee approval was obtained with a waiver for patient informed consent (MEC-U; Research and Development Department St. Antonius Hospital, trial number V15.020).

\section{Data collection and potential confounding factors}

Data regarding medical history and preoperative drug therapy were registered at the outpatient anesthesia clinic during routine preoperative screening. Standard laboratory hematology and coagulation parameters were retrieved from the hospital electronic patient records. Information regarding surgery, $\mathrm{CPB}$, transfusion products and postoperative blood loss were collected from computerized perioperative medical records (Metavision Suite 5.46.44, iMDsoft ${ }^{\oplus}$, Düsseldorf, Germany).

Prior to analysis, variables that were potentially associated with $\mathrm{RBC}$ transfusion were specified based on previous literature reports and biological plausibility including: age, sex, body mass index (BMI), preoperative $\mathrm{Hb}$ concentration, preoperative creatinine concentration, smoking, chronic obstructive pulmonary disease (COPD), hypertension, diabetes, peripheral artery disease, previous stroke, left ventricular ejection fraction (LVEF), previous cardiac surgery, unstable angina, emergency surgery, duration of operation time, autologous red blood cell transfusion, use of an internal mammary artery and type of surgery $[11,12]$.

\section{Outcome measures}

The primary outcome measure was postoperative mortality within 30 days after surgery, further denominated as mortality. Registration of mortality was conducted in the context of a national registry of cardiac interventions in The Netherlands (Netherlands Heart Registry) [13].

\section{Clinical management}

\section{Anesthesia management and cardiopulmonary bypass}

During the study period antiplatelet therapy (APT) was routinely discontinued 5 to 10 days prior to an elective surgical procedure. Routine perioperative anesthesia care included induction of anesthesia with midazolam, propofol, fentanyl and pancuronium and maintenance of anesthesia with propofol and fentanyl or remifentanyl. Vasoactive medications e.g. norepinephrine, dopamine, enoximone and nitroglycerine were used by discretion of the attending anesthetist. All patients received antimicrobial prophylaxis (cefazolin) at induction of anesthesia followed by additional cefazolin every $4 \mathrm{~h}$ for the duration of surgery and for $48 \mathrm{~h}$ in case of valve replacement. Intraoperative TEE as part of hemodynamic monitoring was routinely performed during valve surgery. In isolated CABG, use of TEE monitoring was left to the discretion of the attending anesthetist.

$\mathrm{CPB}$ consisted of a miniaturized extracorporeal circulation (MECC) or a conventional extracorporeal circulation (ECC) according to the preference of the surgeon and type of procedure. For $\mathrm{CPB}$, non-pulsatile perfusion was used with a flow of 2.0 to $2.4 \mathrm{~L} / \mathrm{min} / \mathrm{m}^{2}$. All patients received heparin before $\mathrm{CPB}$ to achieve an adequate kaolin activated clotting time (ACT > $300 \mathrm{~s}$ for MECC and > $400 \mathrm{~s}$ for ECC). Additional heparin was administered when needed to keep ACT on target. After aortic cross-clamping, cardiac arrest was initiated using a cold crystalloid or blood (in case of MECC) cardioplegia solution. During $\mathrm{CPB}$ patients were cooled to a rectal temperature of $32{ }^{\circ} \mathrm{C}$ to $34^{\circ} \mathrm{C}$. Patients were weaned from $\mathrm{CPB}$ after rectal temperature reached $35.5^{\circ} \mathrm{C}$. In general, intraoperative management targeted a $\mathrm{SvO}_{2}$ of $65 \%$ and a MAP of $50 \mathrm{mmHg}$ during $\mathrm{CPB}$. According to institutional recommendations, heparin was reversed with protamine sulphate, $1 \mathrm{mg}$ for every $100 \mathrm{U}$ of previously administered heparin.

After surgery patients were transferred to the ICU and weaned from mechanical ventilation after exhibiting complete recovery from anesthesia, hemodynamically stability with no evidence of significant bleeding, core temperature $>36^{\circ} \mathrm{C}$ and normal blood gas values. Patients were discharged from the ICU the following morning after meeting institutional discharge criteria.

\section{Blood transfusion management}

Blood product transfusion was performed according to a local transfusion protocol. The trigger for intraoperative $\mathrm{RBC}$ transfusion was a hematocrit $<20 \%$ during $\mathrm{CPB}$ or $<25 \%$ after separation from $\mathrm{CPB}$. After surgery, $\mathrm{RBC}$ transfusion was at the discretion of the attending ICU physician and based on postoperative hemodynamics and chest tube output. A postoperative $\mathrm{Hb}$ value of $4.5 \mathrm{mmol} / \mathrm{l}(7.3 \mathrm{~g} / \mathrm{dL})$ was an absolute trigger for RBC transfusion.

Intraoperative plasma transfusion was based on the amount of blood loss; i.e. the number of transfused cell saver units or clinical signs of coagulopathy after protamine administration. Platelet transfusion depended on clinical signs of coagulopathy in combination with low platelet count $\left(<100 \times 10^{9} / \mathrm{l}\right)$ or continuation of APT during surgery. The final decision for blood product transfusion was at the discretion of the attending physician.

Administration of factor concentrates was not part of routine blood management. Point-of-care hemostatic monitoring was implemented in Q2 of 2015 as a part of routine blood management. Intraoperative tranexamic acid use was 
left to the discretion of the attending anesthetist. Intraoperative cell salvage was routinely used.

\section{Statistical analysis}

Categorical data are stated as number and percentages. Chi-square test or Fisher's exact test were used to compare dichotomous variables between groups. Continuous data are described as median and interquartile range (IQR) as all continuous variables were non-normally distributed. The P-P plot was used to check for normality in distribution. Mann-Whitney U test or Student's t-test was used to compare independent continuous variables between groups. To estimate the odds ratio for mortality in patients receiving intraoperative $\mathrm{RBC}$ transfusion a logistic regression analysis was performed using a propensity score (PS) as single confounder [14]. To define high-risk subgroups patients were stratified into four groups of equal size (quartiles) based on the sample distribution of the PS. Differences among quartiles were analysed using Mann-Whitney U test or Student's t-test. A subgroup analysis was performed in the group of patients at highest risk of $\mathrm{RBC}$ transfusion $(\mathrm{Q} 4)$ using multivariate regression analysis. A $p$ value $<0.05$ was considered statistically significant. For statistical analysis IBM SPSS version 22 (IBM Corp. Released 2013, SPSS Statistics for Windows, Version 22.0. Armonk, NY: IBM Corp.) was used.

\section{Propensity score}

The PS was constructed beforehand and represented the likelihood of receiving RBC transfusion based on pre- and intraoperative characteristics. Variables that were potentially associated with RBC transfusion were included in a multivariable logistic regression analysis and included age, sex, BMI, smoking, COPD, hypertension, diabetes, peripheral artery disease, previous stroke, LVEF, previous cardiac surgery, unstable angina, emergency surgery, additive EuroSCORE, preoperative $\mathrm{Hb}$ concentration, duration of operation time, autologous RBC transfusion, use of an internal mammary artery and type of surgery.

\section{Results}

\section{Study population and baseline characteristics}

A total of 2933 patients were included in the study. Mean age was 67 years $( \pm 10)$ and $78 \%$ of patients were male. Most common comorbidities were hypertension (61\%), diabetes mellitus (25\%) and peripheral artery disease (12\%). Median EuroSCORE was four [2-6] and 729 (25\%) patients had a reduced LVEF ( $\leq 50 \%$ ) prior to surgery. A majority of patients (87\%) underwent isolated CABG surgery, IMA was used for grafting in $91 \%$ of cases and median duration of operation was $195 \mathrm{~min}$ [165-233]. In 209 patients (7\%) an emergency procedure was performed. After surgery postoperative $12 \mathrm{~h}$ drain production was $580 \mathrm{ml}$ [440-820] and postoperative $\mathrm{Hb}$ was $6.0 \mathrm{mmol} / \mathrm{l}$ [5.4-6.7] (9.7 g/dL [8.7-10.8]). In 3\% of patients drain production exceeded $2000 \mathrm{ml} / 12 \mathrm{~h}$. The median ICU length of stay was $21 \mathrm{~h} \mathrm{[18-43]} \mathrm{and} 123$ (5\%) patients had a re-sternotomy.

\section{Intra-operative transfusions}

A total of $647(22 \%)$ patients received a median of 3 [2-4] units of any intraoperative allogeneic transfusion. Plasma transfusion occurred in 210 patients (7\%) with a median of 2 [2] units and platelet transfusion was performed in 567 patients (19\%) with a median of $1[1,2]$ units. A total of 967 intraoperative RBC units were given to 488 patients (17\%). Median number of transfused RBC units was 2 [1, 2]. Two-hundred-ninety-three patients $(10 \%)$ received 2 or more RBC units. In patients with RBC transfusion, median $\mathrm{Hb}$ concentration at the end of surgery was $5.6 \mathrm{mmol} / \mathrm{l}$ [5.1-6.1] (9.0 g/dL [8.2-9.3]) versus $6.1 \mathrm{mmol} / \mathrm{l}$ [5.5-6.8] $(9.3 \mathrm{~g} / \mathrm{dL}$ [8.9-11.0]) in patients without RBC transfusion $(P<0.001)$. Table 1 shows differences in baseline characteristics of study patients according to intra-operative RBC transfusion before and after PS adjustment.

\section{Propensity model}

The adjustment for PS adequately balanced the groups for the baseline variables with exception of preoperative $\mathrm{Hb}$ (Table 1). There was some overlap for PS distributions between groups $(0.5 \pm 0.30$ (range $0.0-1.0)$ for patients with RBC transfusion vs. $0.1 \pm 0.15$ (range 0.0 0.93 ) for patients without RBC transfusion; $P<0.001$ ).

\section{Intra-operative RBC transfusion and postoperative mortality}

Sixty patients (2\%) died within 30 days after surgery. Sixty-two percent of patients who died had intra-operative $\mathrm{RBC}$ transfusion compared to $16 \%$ of survivors $(P<0.001)$. After propensity score adjustment, intraoperative RBC transfusion was associated with a more than three-fold mortality risk (OR $3.1 ; 95 \%$ CI $1.5-6.7 ; P=0.003)$.

\section{Subgroup analysis in patients with high probability of transfusion}

Table 2 presents differences in risk factors for mortality after stratification into quartiles according to PS. Patients with the highest probability of transfusion (Q4) were older (age 75 vs 66 for Q1-Q3; $P<0.001$ ), had a higher EuroSCORE (6 vs 3 for Q1-Q3; $P<0.001)$, had lower preoperative hemoglobin levels $(7.6 \mathrm{mmol} / \mathrm{l}(12.3 \mathrm{~g} / \mathrm{dl})$ vs $8.9 \mathrm{mmol} / \mathrm{l}(14.3 \mathrm{~g} / \mathrm{dl})$ for Q1-Q3; $P<0.001)$, had combined surgery more often (CABG + AVR in $33.4 \%$ of cases vs $6.6 \%$ in Q1-Q3 $(P<$ 0.001 ) and a longer duration of surgery (224 vs $188 \mathrm{~min}$ for Q1-Q3; $P<0.001)$. Mortality was highest in Q4 (5.1\% compared to $0.4,0.7$ and $2.2 \%$ in Q1-3 respectively). In patients with the highest probability of transfusion intraoperative RBC transfusion was associated with a 4.1-fold risk of mortality (PS adjusted OR 4.1 and 95\% CI 1.3-12.6, $P=0.016$ ). In $\mathrm{Q} 4, \mathrm{OR}$ for $\mathrm{RBC}$ associated mortality changed with $7 \%$ 
Table 1 Baseline characteristics according to intraoperative RBC transfusion

\begin{tabular}{|c|c|c|c|c|}
\hline & $\begin{array}{l}\text { No } R B C \text { transfusion } \\
(n=2445)\end{array}$ & $\begin{array}{l}\text { RBC transfusion } \\
(n=488)\end{array}$ & $\begin{array}{l}\text { Unadjusted } \\
p \text {-value }\end{array}$ & $\begin{array}{l}\text { PS adjusted } \\
p \text {-value }\end{array}$ \\
\hline \multicolumn{5}{|l|}{ Patient characteristics } \\
\hline Male gender, n (\%) & $2026(82.9)$ & $249(51)$ & $<0.001$ & 0.403 \\
\hline Age, yr & $66(60-73)$ & $74(68-79)$ & $<0.001$ & 0.296 \\
\hline $\mathrm{BMl}, \mathrm{kg} / \mathrm{m} 2$ & $27(25-30)$ & $26(24-29)$ & 0.001 & 0.684 \\
\hline Smoking, n (\%) & $756(30.9)$ & $116(23.8)$ & 0.002 & 0.795 \\
\hline Chronic obstructive pulmonary disease, n (\%) & $279(11.4)$ & $66(13.5)$ & 0.365 & 0.984 \\
\hline Hypertension, n (\%) & $1466(60.0)$ & $321(65.8)$ & 0.016 & 0.688 \\
\hline Diabetes, n (\%) & $567(23.2)$ & $166(34.0)$ & $<0.001$ & 0.617 \\
\hline Peripheral artery disease, $\mathrm{n}(\%)$ & $252(10.3)$ & $90(18.4)$ & $<0.001$ & 0.688 \\
\hline Previous stroke, n(\%) & $161(6.6)$ & $50(10.2)$ & 0.004 & 0.708 \\
\hline Previous cardiac surgery, n (\%) & $60(2.5)$ & $33(6.8)$ & $<0.001$ & 0.894 \\
\hline Reduced LVEF (<50\%), n(\%) & $572(23.4)$ & $157(32.2)$ & $<0.001$ & 0.835 \\
\hline Unstable angina, n (\%) & $155(6.3)$ & $72(14.8)$ & $<0.001$ & 0.858 \\
\hline Emergency procedure, n (\%) & $156(6.4)$ & $53(10.9)$ & 0.001 & 0.948 \\
\hline EurOSCORE & $3(2-5)$ & $6(4-8)$ & $<0.001$ & 0.290 \\
\hline \multicolumn{5}{|l|}{ Laboratory } \\
\hline $\mathrm{Hb}, \mathrm{mmol} / \mathrm{l}$ & $8.8(8.2-9.3)$ & $7.6(7.0-8.4)$ & $<0.001$ & 0.029 \\
\hline Creatinine, $\mu \mathrm{mol} / \mathrm{l}$ & 83 [73-96] & 85 [71-109] & $<0.001$ & 0.911 \\
\hline \multicolumn{5}{|l|}{ Procedural characteristics } \\
\hline Duration of procedure, min & $190[161-227]$ & 223 [186-265] & $<0.001$ & 0.652 \\
\hline Use of IMA, n (\%) & $2251(92.1)$ & $412(84.4)$ & $<0.001$ & 0.927 \\
\hline Salvaged red cell volume reinfused (units) & $1.8[1.0-2.0]$ & $2.0[1.0-3.0]$ & $<0.001$ & 0.809 \\
\hline CABG, n (\%) & $2225(91.0)$ & $330(67.6)$ & $<0.001$ & 0.875 \\
\hline CABG + AVR, n (\%) & $220(9.0)$ & $158(32.4)$ & $<0.001$ & 0.875 \\
\hline
\end{tabular}

Data are presented as median (IQR), or frequencies ( $\mathrm{n},(\%))$

$P S$ propensity score, $R B C$ red blood cell, $B M I$ body mass index, $L V E F$ left ventricular ejection fraction, $H b$ hemoglobin, IMA internal mammary artery

after adding plasma transfusion to the PS adjusted mortality (OR 3.8, $P=0.021$ ). After adjustment for differences in age, EuroSCORE, preoperative $\mathrm{Hb}$, type and duration of surgery, the OR for mortality in patients with intraoperative $\mathrm{RBC}$ transfusion in Q4 was 2.6 (95\% CI 1.3-5.1, $P=0.007)$.

\section{Discussion}

This historical cohort study in patients undergoing coronary surgery showed that intraoperative $\mathrm{RBC}$ transfusion was associated with a more than three-fold increased risk for mortality. The association between intraoperative

Table 2 Differences in patient characteristics, RBC transfusion and mortality according to propensity score subgroups

\begin{tabular}{|c|c|c|c|c|c|c|c|c|}
\hline & \multicolumn{2}{|l|}{$\mathrm{Q} 1(n=683)$} & \multicolumn{2}{|l|}{$\mathrm{Q} 2(n=684)$} & \multicolumn{2}{|l|}{ Q3 $(n=684)$} & \multicolumn{2}{|l|}{$\mathrm{Q} 4(n=683)$} \\
\hline & $\mathrm{RBC}-(n=672)$ & $\mathrm{RBC}+(n=11)$ & $\mathrm{RBC}-(n=665)$ & $\mathrm{RBC}+(n=19)$ & $\mathrm{RBC}-(n=612)$ & $\mathrm{RBC}+(n=72)$ & $\mathrm{RBC}-(n=360)$ & $\mathrm{RBC}+(n=323)$ \\
\hline Age, y & 63 [56-68] & 61 [57-65] & 66 [59-71] & 68 [64-77] & 70 [63-75] & 69 [63-76] & 74 [68-79] & 75 [71-80] \\
\hline EurOSCORE & $2[1-4]$ & $2[1-2]$ & $3[1-4]$ & $4[2-6]$ & $4[3-6]$ & $4[3-6]$ & $6[5-8]$ & $7[5-9] * *$ \\
\hline $\begin{array}{l}\text { Hemoglobin, } \\
\mathrm{mmol} / \mathrm{l}\end{array}$ & $9.5[9.1-9.8]$ & 9.6 [9.3-9.8] & $8.8[8.5-9.2]$ & 8.9 [8.4-9.1] & $8.4[8.0-8.8]$ & $8.5[8.0-8.8]$ & $7.8[7.2-8.3]$ & $7.4[6.8-7.9]^{* *}$ \\
\hline $\begin{array}{l}\text { CABG + AVR, } \\
n(\%)\end{array}$ & $9(1)$ & 0 & $36(5)$ & 0 & $78(13)$ & $13(18)$ & $89(28)$ & $139(39)^{* * *}$ \\
\hline $\begin{array}{l}\text { Duration } \\
\text { procedure, min }\end{array}$ & 172 [148-199] & 142 [115-230] & 197 [169-226] & 189 [178-225] & 200 [169-236] & 206 [177-235] & 214 [180-252] & $\underset{* *}{229}[195-275]$ \\
\hline Mortality, n (\%) & $3(0.4)$ & 0 & $5(0.8)$ & 0 & $11(1.8)$ & $4(5.6) *$ & $4(1.1)$ & $31(9.6)^{* *}$ \\
\hline
\end{tabular}

Data are presented as median $[\mathrm{IQR}]$ or frequencies $(\mathrm{n},(\%)) . \mathrm{Q}=$ quartile. Hemoglobin = preoperative value

Within stratum baseline covariate comparison between RBC transfused and not transfused patients was significant in the highest quartile $*=P<0.05, * *=P<0.01$ 
transfusion and mortality remained present in a subgroup of patients with high probability of RBC transfusion after adjustment for multiple risk factors.

Anemia predisposes to myocardial ischemia in patients with coronary disease, especially during cardiac surgery when ongoing blood loss and hemodilution lower the oxygen carrying capacity of blood. Intraoperative RBC transfusion is a common but potential harmful treatment of anemia, which emphasizes the paradox that both anemia and transfusion are associated with adverse outcome in cardiac surgery patients [1-8]. This raises the question to what extend anemia should be accepted during coronary surgery and when RBC transfusion becomes ineluctable. The recent TRICS III study has provided further insight in RBC transfusion thresholds in cardiac surgery patients. In a multicenter trial patients undergoing on-pump cardiac surgery were randomized to a restrictive $(<7.5 \mathrm{~g} / \mathrm{dL})$ or liberal $(<9.5 \mathrm{~g} / \mathrm{dL}) \mathrm{RBC}$ transfusion strategy, in the operating room and intensive care unit. After 6 months follow up a perioperative restrictive transfusion strategy was non-inferior to a liberal strategy in terms of a composite endpoint including death, myocardial infarction, stroke or new onset renal failure [15]. In our cohort, the median $\mathrm{Hb}$ concentration at the end of surgery in patients with $\mathrm{RBC}$ transfusion was $5.6 \mathrm{mmol} / \mathrm{l}(9.0 \mathrm{~g} / \mathrm{dL})$ and substantially higher than the restrictive transfusion threshold in TRICS III. These results suggest that increased mortality rates in our study population are more likely to be associated with $\mathrm{RBC}$ transfusion than intraoperative anemia. In addition, when considering the general rule of thumb that a single unit of red cells results in an $\mathrm{Hb}$ increment of $1 \mathrm{~g} / \mathrm{dL}$, transfusion of a single RBC unit could have been withheld in 348 patients [16].

Despite transfusion guidelines in cardiac surgery patient blood management varies between physicians. Especially in surgical patients at older age or with more extensive comorbidity a tendency exists towards a more liberal transfusion strategy [17-19]. This was confirmed by the results of our study, patients with the highest probability of $\mathrm{RBC}$ transfusion were characterized by older age, a higher EuroSCORE and more complex surgery. These findings illustrate that besides $\mathrm{Hb}$ concentration anesthetists and surgeons consider multiple clinical factors in their treatment decision for intraoperative transfusion. However, also in more vulnerable patients $\mathrm{RBC}$ transfusion has been associated with increased risk for adverse outcome. In the TITRE2 study a liberal transfusion strategy $(\mathrm{Hb}>9.0 \mathrm{~g} / \mathrm{dL})$ was compared to a restrictive transfusion strategy $(\mathrm{Hb}>7,5 \mathrm{~g} / \mathrm{dL})$ in a multi-centre, randomized, controlled trial in adult patients after cardiac surgery [9]. Secondary analyses that studied the effect of transfusion showed that patients with older age, higher logistic EuroSCOREs and longer duration of surgery were more likely to be treated with $\mathrm{RBC}$ transfusion [19]. Mortality in patients with $\mathrm{RBC}$ transfusion was higher (3.7\%) compared to non-transfused participants (2.7\%) [19]. The recent TRICS III trial also studied the impact of a liberal versus restrictive transfusion strategy in cardiac surgery patients, but had a different design [15]. Patients were randomized prior to surgery and intra-operative $\mathrm{RBC}$ transfusion management was part of the study protocol. In that study, a sensitivity analysis of patients 75 years or older showed that a restrictive transfusion strategy appeared to be superior to a liberal strategy with regard to the composite endpoint of death, myocardial infarction and new renal failure requiring dialysis (OR 0.77 and 95\% CI 0.62-0.96, $P=0.001$ ) [15]. Although both TITRE2 and TRICS III have not primarily focused on the optimal transfusion trigger in the older cardiac surgery population, the results of subgroup analyses demonstrate that especially in older more frail patients intra-operative $\mathrm{RBC}$ transfusion seems to be associated with increased risk for adverse outcome.

Although coronary surgery patients are potentially more vulnerable to anemia due to fixed coronary stenosis, a restrictive $\mathrm{RBC}$ transfusion strategy in patients with stable cardiovascular disease is now considered relatively safe and has been recommended in recent literature reports [20-24]. It seems to become increasingly clear that myocardial revascularization primarily obviates the ischemic complications and that intraoperative anemia $(\mathrm{Hb}>7.5 \mathrm{~g} / \mathrm{dL})$ plays no major role in adverse outcome. These findings may justify a restrictive transfusion strategy, especially in the operating room, where anemia is often the result of hemodilution and at least partially reversible. Additionally, during surgery the oxygen needs of tissues are reduced due to anesthesia and hypothermia. To further reduce the risk of intraoperative $\mathrm{RBC}$ transfusion clinicians should focus on diagnosing and treating preoperative anemia, especially in older patients and/or those with multiple comorbidities.

This analysis has some limitations, although our historical cohort study resembles real-world practice the results may have been influenced by confounding factors. Instead of random transfusion allocation based on a predefined transfusion trigger (as in randomized trials), $\mathrm{RBC}$ transfusion decision were based on a combination of a local transfusion protocol and individual physician preferences. Therefore, to assess the outcome between patients with and without intraoperative RBC transfusion propensity score analysis was used to account for systematic differences in baseline characteristics between patients with and without transfusion. However unmeasured confounders may have influenced the association between RBC transfusion and mortality. This study was a retrospective observational investigation before point-of-care driven patient blood management was 
standard practice in our operating theatre and covers a period in which the available evidence regarding restrictive RBC transfusion strategy was limited. Since then it has become increasingly clear that reducing transfusion rates with evidence-based patient blood management programs can provide significant clinical and economic advantages. At last, this study reports a short term negative association with intraoperative $\mathrm{RBC}$ transfusion while transfusion may have long-term consequences.

\section{Conclusion}

Intra-operative transfusion of red blood cells was found to be associated with increased mortality in adults undergoing coronary surgery. Future work should focus on reducing the probability of intraoperative RBC transfusion by preoperative patient optimization and treatment of preoperative anemia.

\section{Abbreviations}

ACT: Kaolin activated clotting time; APT: Anti-platelet therapy; AVR: Aortic valve replacement surgery; BMI: Body mass index; CABG: Coronary artery bypass grafts surgery; COPD: Chronic obstructive pulmonary disease; CPB: Cardio-pulmonary bypass; ECC: Conventional extracorporeal circulation; $\mathrm{Hb}$ : Hemoglobin level; ICU: Intensive care unit; IMA: Internal mammary artery; IQR: Interquartile range; LVEF: Left ventricular ejection fraction; MECC: Miniaturized extracorporeal circulation; OR: Odds ratio; PS: Propensity score; Q: Quartile; RBC: Red blood cell transfusion

\section{Acknowledgements}

Not applicable

\section{Funding}

There was no external funding. This work was supported by departmental sources.

\section{Availability of data and materials}

The datasets used and/or analysed during the current study are available from the corresponding author on reasonable request and should remain within the confines of Dutch law regarding confidentiality.

\section{Authors' contributions}

EV: study design, analysis and interpretation of data and writing of the article and revision of the manuscript. LV: analysis and interpretation of the data. EG: interpretation of data and statistical analysis. GK: critical revision of the manuscript. ED: study design and critical revision the manuscript. PN: study design, interpretation of data, writing of the article and contribution in revising the manuscript. All authors have read and approved the final manuscript.

\section{Ethics approval and consent to participate}

Local Medical Research Ethics Committee approval was obtained with a waiver for patient informed consent (MEC-U; Research and Development Department St. Antonius Hospital, trial number V15.020).

\section{Consent for publication}

Not applicable

\section{Competing interests}

The authors declare that they have no competing interests.

\section{Publisher's Note}

Springer Nature remains neutral with regard to jurisdictional claims in published maps and institutional affiliations.

\section{Author details}

'Department of Anesthesiology, Intensive Care and Pain Medicine, St Antonius Hospital, Koekoekslaan 1, 3430 EM Nieuwegein, The Netherlands. ${ }^{2}$ Department of Clinical Pharmacy, St Antonius Hospital, Nieuwegein, The Netherlands. ${ }^{3}$ Department of Cardiac Surgery, St Antonius Hospital, Nieuwegein, The Netherlands.

Received: 18 December 2018 Accepted: 18 April 2019

Published online: 04 May 2019

\section{References}

1. Karkouti K, Wijeysundera DN, Beattie WS. Reducing bleeding in cardiac surgery (RBC) investigators. Risk associated with preoperative anemia in cardiac surgery: a multicenter cohort study. Circulation. 2008;117:478-84.

2. Miceli A, Romeo F, Glauber M, et al. Preoperative anemia increases mortality and postoperative morbidity after cardiac surgery. J Cardiothorac Surg. 2014;9:137.

3. Hogervorst EK, Rosseel PM, van de Watering LM, et al. Intraoperative Anemia and single red blood cell transfusion during cardiac surgery: an assessment of postoperative outcome including patients refusing blood transfusion. J Cardiothorac Vasc Anesth. 2016;30:363-72.

4. Koch CG, Li L, Duncan Al, et al. Morbidity and mortality risk associated with red blood cell and blood-component transfusion in isolated coronary artery bypass grafting. Crit Care Med. 2006:34:1608-16.

5. Murphy GJ, Reeves BC, Rogers CA, et al. Increased mortality, postoperative morbidity, and cost after red blood cell transfusion in patients having cardiac surgery. Circulation. 2007;116:2544-52.

6. Hajjar LA, Vincent JL, Galas FR, et al. Transfusion requirements after cardiac surgery: the TRACS randomized controlled trial. JAMA. 2010;304:1559-67.

7. Bhaskar B, Dulhunty J, Mullany DV, et al. Impact of blood product transfusion on short and long-term survival after cardiac surgery: more evidence. Ann Thorac Surg. 2012;94:460-7.

8. Paone G, Likosky DS, Brewer R, et al. Membership of the Michigan Society of Thoracic and Cardiovascular Surgeons. Transfusion of 1 and 2 units of red blood cells is associated with increased morbidity and mortality. Ann Thorac Surg. 2014;97:87-93 discussion 93-4.

9. Murphy GJ, Pike K, Rogers CA, et al. TITRe2 investigators. Liberal or restrictive transfusion after cardiac surgery. N Engl J Med. 2015;372:9971008.

10. Mazer CD, Whitlock RP, Fergusson DA, et al. TRICS investigators and perioperative anesthesia clinical trials group. Restrictive or Liberal red-cell transfusion for cardiac surgery. N Engl J Med. 2017;377:2133-44.

11. Despotis GJ, Filos KS, Zoys TN, et al. Factors associated with excessive postoperative blood loss and hemostatic transfusion requirements: a multivariate analysis in cardiac surgical patients. Anesth Analg. 1996;82: 13-21.

12. Van Straten AH, Kats S, Bekker MW, et al. Risk factors for red blood cell transfusion after coronary artery bypass graft surgery. J Cardiothorac Vasc Anesth. 2010;24:413-7.

13. Supervisory Committee for Cardiac Interventions in The Netherlands (Begeleidingscommissie Hartinterventies Nederland, BHN). [cited 2017 Jun 2]. Available from: www.nederlandsehartregistratie.nl

14. Rosenbaum PR, Rubin DB. The central role of the propensity score in observational studies for causal effects. Biometrika. 1983;70:41-55.

15. Mazer CD, Whitlock RP, Fergusson DA, et al. TRICS investigators and perioperative anesthesia clinical trials group. Six-month outcomes after restrictive or Liberal transfusion for cardiac surgery. N Engl J Med. 2018;379: 1224-33.

16. Wiesen AR, Hospenthal DR, Byrd JC, et al. Equilibration of hemoglobin concentration after transfusion in medical inpatients not actively bleeding Ann Intern Med. 1994;121:278-30.

17. Brown CH IV, Savage WJ, Masear CG, et al. Odds of transfusion for older adults compared to younger adults undergoing surgery. Anesth Analg. 2014;118:1168-78.

18. Ad N, Massimiano PS, Burton NA, et al. Effect of patient age on blood product transfusion after cardiac surgery. J Thorac Cardiovasc Surg. 2015; 150:209-14.

19. Reeves BC, Pike K, Rogers CA, et al. A multicentre randomised controlled trial of transfusion indication threshold reduction on transfusion rates, morbidity and health-care resource use following cardiac surgery (TITRe2). Health Technol Assess. 2016;20:1-260. 
20. Carson JL, Stanworth SJ, Roubinian N, et al. Transfusion thresholds and other strategies for guiding allogeneic red blood cell transfusion. Cochrane Database Syst Rev. 2016;10:CD002042.

21. Boer C, Meesters MI, Milojevic M, et al. Task force on patient blood Management for Adult Cardiac Surgery of the European Association for Cardio-Thoracic Surgery (EACTS) and the European Association of Cardiothoracic Anaesthesiology (EACTA). 2017 EACTS/EACTA guidelines on patient blood management for adult cardiac surgery. J Cardiothorac Vasc Anesth. 2018:32:88-120.

22. Carson JL, Stanworth S, Alexander JH, et al. Clinical trials evaluating red blood cell transfusion thresholds: an updated systematic review and with additional focus on patients with cardiovascular disease. Am Heart J. 2018; 200:96-101.

23. Carson JL, Guyatt G, Heddle NM, et al. Clinical practice guidelines from the AABB: red blood cell transfusion thresholds and storage. JAMA. 2016; 316(19):2025-35

24. Hayes MM, Uhl L. To transfuse or not transfuse: an intensive appraisal of red blood cell transfusions in the ICU. Curr Opin Hematol. 2018;25:468-72.

Ready to submit your research? Choose BMC and benefit from:

- fast, convenient online submission

- thorough peer review by experienced researchers in your field

- rapid publication on acceptance

- support for research data, including large and complex data types

- gold Open Access which fosters wider collaboration and increased citations

- maximum visibility for your research: over $100 \mathrm{M}$ website views per year

At BMC, research is always in progress.

Learn more biomedcentral.com/submissions 